
\title{
R Reserach S Suare \\ Living with chronic headaches: A qualitative study from an outpatient pain clinic in Norway
}

\section{Jill Brook Hervik}

Vestfold Hospital Trust: Sykehuset i Vestfold HF

Eva B. Foss

Vestfold Hospital Trust: Sykehuset i Vestfold HF

Trine Stub ( $\nabla$ trine.stub@uit.no)

UiT Arctic University of Norway: UiT Norges arktiske universitet

Research article

Keywords: Chronic headache, pain, quality of life, emotional and behavioural changes, embodiment

Posted Date: May 5th, 2021

DOl: https://doi.org/10.21203/rs.3.rs-479614/v1

License: (c) (i) This work is licensed under a Creative Commons Attribution 4.0 International License.

Read Full License 


\section{Abstract}

Chronic headaches are poorly managed in primary care despite a high level of morbidity. The aim of this study was to gain subjective information regarding the lives of chronic headache sufferers.

Method

This focused ethnography draws from in-depth, semi-structured interviews conducted with 16 patients who suffered from chronic headaches. Five main domains were explored in the data analysis: emotions related to headaches; trauma/stressful events; headache as a driver of behaviour; family bonding and coping mechanisms. Headache as a driver of behaviour had three subdomains: shame; loss of identity and lack of freedom.

Results

Participants reported that pain restricted their lives in many ways. Issues included not being able to work full time and different levels of dependency on disability pension. The majority believed that trauma was the reason for their headaches. Shame and loss of identity appeared to be strongly associated with chronic pain.

Conclusion

This study demonstrates that chronic headaches restrict sufferers' lives, resulting in emotional and behavioural changes. Traumatic events of varying degrees throughout the course of life can initiate and maintain symptoms, which may become chronic and thereby have socio economic consequences, for individuals and society in general. Clinicians need to have an increased awareness as to the complexity of chronic headaches.

Perspective

This article presents information regarding the lives of chronic headache sufferers. The findings suggests that these patients need a multidisciplinary treatment approach

\section{Introduction}

Although headache is considered a frequently experienced type of pain, chronic headache and intractable migraine can lead to a serious reduction in function and quality of life [1]. The Global Burden of Disease Study 2010 [2] ranked migraine as the third most prevalent disorder worldwide, and the third highest cause of disability in both men and women under 50 years of age. The World Health Organization (WHO) has highlighted the financial burden that headache disorders have on economies at all levels, while at the same time emphasising the lack of importance generally attributed to these conditions [3]. 
Summarizing the data from a review of headache and migraine in Europe [4] the proportion of adults reporting migraine is $14 \%$ and chronic headache is $4 \%$. A survey of over 4000 people in England showed that $7.6 \%$ of males and $18.3 \%$ of females experienced migraine with or without aura within the last year [5]. Confirming diagnostic criteria stipulated by the international headache Society (chronic daily headaches for at least 15 days or more a month, for longer than three months) [6]. In some cases, patients with chronic headaches suffer headaches of such persistence that it becomes impossible to distinguish individual episodes of pain [7]. The escalation from episodic headaches to chronic headaches is associated with a high degree of disability, affecting the lives of not just the sufferer but families and employment situations, provoking personal and financial costs [8].

Based on data from the Nord-Trøndelag Health Study (HUNT) performed in 2006-2008 (HUNT3) and 2017-2019 (HUNT4) in Norway, a higher proportion of participants in HUNT4 reported having tensiontype headaches compared to participants in HUNT $3(20.7 \%$ vs. $15.9 \%, p<0.001)$, whereas a lower 1-year prevalence was found for migraine $(11.1 \%$ vs. $12.0 \%, p<0.001)$ and medication overuse headache $(0.3 \%$ vs. $1.0 \%, p<0.001)$. Female sex, occurrence of chronic musculoskeletal complaints, and a high depression or anxiety score at baseline, doubled the risk of headache incidence in these surveys [9].

Although headaches are a frequently experienced type of pain, chronic headaches can lead to a serious reduction in function and quality of life. The International Headache Society (6) has introduced international guidelines for the organization of headache service and management, however there is no single standard of care for patients presenting with primary chronic headache symptoms. Treatment is often initiated by the patients themselves without any medical consultation. Guideline recommendations for self-medication is a standard dose combination of paracetamol, aspirin and caffeine; or monotherapy with ibuprofen, naratriptan, or paracetamol as first line therapy [10]. For migraine, triptans in general are preferred over non-specific treatment [11].

Although there has been significant improvement in the management of primary headaches including migraine, inadequate response to medications, estimating dosage and adverse effects pose challenges. In general, the population does not easily understand chronic headaches. Symptoms are largely invisible. Sufferers often feel that they are not believed, many go as far as to say that they are ridiculed. Personal experiences of illness relating to emotions, relationships and aspirations are aspects not easily measured by questionnaires and are therefore not suited to quantitative methods [12].

\section{Theory}

\section{The impact of stressful life events on health}

Sutin AR et al [13], reported that stressful life events are associated with changes in self-rated health across a 10-year time span. Stress is also related to an increase in chronic daily headaches (1). Research demonstrates that chronic migraines and daily headaches are more likely in divorced, widowed, or separated people [14]. The life course approach (13) offers an interdisciplinary framework to understand 
health, human development, and aging. It brings together psychological, cognitive, and biological research on developmental processes from conception to death. This framework is based on the premise that various biological and social factors throughout life independently, cumulatively, and interactively influence health and disease in adult life [14]. The concept explains how socially patterned exposures during childhood, adolescence, and early adult life influence adult disease risk and socioeconomic position, possibly accounting for social inequalities in adult health and mortality [15]. The life course approach has much in common with the theory of Habitus developed by Pierre Bourdieu $[16,17]$ who referred to habitus as the embodiment of history. Habitus is significant in that it reminds us of how social subjects have a history and a course of life [18]. In other words, we are the product of education and an individual and collective history, directly influenced by social environment. Thus intellect, thoughts, perceptions, and evaluations are nothing other than products of the embodiment of social structures [17, 19]. Embodiment describes how extrinsic factors experienced at different stages are inscribed into an individual's body functions or structures [20].

Qualitative research has been used to analyse how migraine affects work, leisure, social and family life $[21,22]$. There are fewer studies regarding only chronic headaches. One systematic review and synthesis of qualitative literature [23], investigating the lived experience of chronic headaches, included 86 studies. Three main themes emerged when results were analysed: headache as a driver of behaviour, the spectre of headache and strained relationships [23]. These are aspects more suited to qualitative research and are important when treating individuals. A more holistic view is often provided when qualitative research is used, which can be more meaningful to practitioners. By applying qualitative methods, we aim to answer the research question "what is life like, with a chronic headache?" The purpose of this study was to explore the experiences and perspectives of a group of Norwegians suffering from chronic headaches. A literature search revealed that there are no qualitative studies to date, that have focused specifically on Norwegians with chronic headaches.

\section{Aim:}

To explore the lives and experiences of headache sufferers. The main aim of this study was to gain subjective information regarding the lives of chronic headache sufferers. Secondary outcome measures included obtaining information and examples of behaviour in response to having a chronic illness. Also, clarification of the thoughts and feelings of study participants, interpretation of participants' experiences related to their headaches and explanations for their behaviour in different situations, related to symptoms.

\section{Methods}

Anonymity

In this study, we used pseudonyms and randomized identifier numbers (ID) to protect and ensure the anonymities of the participants. 


\section{Qualitative studies}

Subjective information from sufferers obtained in qualitative interviews is necessary in order to improve understanding of how symptoms affect life, both physically and emotionally [24]. Thereby allowing actions to be taken to facilitate improvements in identifying risk factors, pain management and function at work, at home and socially. Qualitative data is especially important in the area of pain management, where an understanding of patient experiences is beneficial, and often unexpected, especially in those with chronic symptoms. Findings will hopefully be useful in clinical settings, especially in the context of resources needed in multidisciplinary treatment approaches. Finally, qualitative studies often provide valuable information that can be utilized in the design of future randomized controlled trials [12].

\section{Study are and setting}

This study was conducted as a focused ethnographic study [12] where the investigators wanted to identify information regarding how chronic headaches affect daily life. The study took place in Norway. Norwegians receive conventional medical treatment either highly subsidized or free of charge, within the public health care system.

\section{Recruitment}

The sample was taken from patients referred to the Vestfold Hospital Trust Hospital pain clinic, from the neurological department and from General Practitioners (GP). Patients who were not referred by a neurologist received a full clinical examination, where baseline recordings were examined to confirm diagnosis. Those included were between 18 and 70 years old with a diagnosis of chronic headache based on criteria from the International Headache Society [6]. Patients who were treated with drugs initiated within 12 weeks prior to inclusion were excluded. As were patients with serious psychiatric or systemic diseases; antipsychotic or opioid medicated patients and those with inadequate Norwegian language skills.

Before completing the interviews, participants were informed about the aim and purpose of the study, and security measures concerning interview content and contact information. Written informed consent was obtained from each individual before conducting and recording the interviews. The study participants were informed that they could withdraw from the study for any reason and at any time, without consequences for future medical treatment. A sample of 16 was perceived enough to achieve saturation [25].

\section{Participants}

Sixteen patients with chronic headache were enrolled. (Table 1: demographic data of the participants). The pain clinic at Vestfold Hospital Trust is located in Tønsberg, Norway. The clinic is organized under the department of anaesthesiology. A multidisciplinary team is composed of medical consultants, a psychologist, a physiotherapist/acupuncturist, cognitive therapists and anaesthesia nurses. Interdisciplinary examinations of patients suffering from chronic pain syndromes aims to identify the 
type(s) and cause(s) of pain, and level of functional disability, in order to tackle the complex issue of pain management.

Table 1: Demographic data of the participants

\begin{tabular}{|c|c|c|c|c|c|c|}
\hline Gender & Age & Marital status & Occupation & $\begin{array}{l}\text { Highest level of } \\
\text { education }\end{array}$ & Children & Work status \\
\hline $\begin{array}{l}\text { Female } \\
\text { (ID9) }\end{array}$ & 60 & Divorced & $\begin{array}{l}\text { Foster mother for adolescents and } \\
\text { emergency home for infants }\end{array}$ & $\begin{array}{l}\text { Lower-level } \\
\text { unlwersitylcollege }\end{array}$ & $\begin{array}{l}\text { One adult child lives full time with } \\
\text { mother }\end{array}$ & $100 \%$ \\
\hline $\begin{array}{l}\text { Male } \\
\text { (ID12) }\end{array}$ & 59 & Married & $\begin{array}{l}\text { Retired police. Works as private } \\
\text { detective } 25 \%\end{array}$ & $\begin{array}{l}\text { Lower-level } \\
\text { universityolcollege }\end{array}$ & Two adult children & $25 \%$ \\
\hline $\begin{array}{l}\text { Female } \\
\text { (ID8) }\end{array}$ & 44 & Cohabitant & Disability pension & $\begin{array}{l}\text { Upper secondary } \\
\text { education }\end{array}$ & $\begin{array}{l}\text { Four children part-time ( } 2 \text { own, } 2 \text { are } \\
\text { partners) }\end{array}$ & $O \&$ \\
\hline $\begin{array}{l}\text { Female } \\
\text { (ID13) }\end{array}$ & 68 & Married & $\begin{array}{l}\text { Retired (former occupational } \\
\text { therapist) }\end{array}$ & $\begin{array}{l}\text { Lower-level } \\
\text { universityjicollege }\end{array}$ & 2 adult children & ON \\
\hline $\begin{array}{l}\text { Male } \\
\text { (ID11) }\end{array}$ & 45 & Married & $\begin{array}{l}\text { Fire service, specialist in fire } \\
\text { prevention }\end{array}$ & Vocational education & Two children & $100 \%$ \\
\hline $\begin{array}{l}\text { Female } \\
\text { (ID1) }\end{array}$ & 44 & Married & Lawyer & Higher-level university & Three children & Sick leave the last three months ( $100 \%$ ) \\
\hline $\begin{array}{l}\text { Female } \\
\text { (ID2) }\end{array}$ & 43 & Divorced/sinde & Loal authority axcountant & $\begin{array}{l}\text { Lower-level } \\
\text { universityokollege }\end{array}$ & Two children (part time) & $\begin{array}{l}40 \% \text { workc } 60 \% \text { work assessment } \\
\text { allowance }\end{array}$ \\
\hline $\begin{array}{l}\text { Fermale } \\
\text { (ID10) }\end{array}$ & so & Married & Social disability nurse & $\begin{array}{l}\text { Lower-level } \\
\text { universityleollege }\end{array}$ & Two children & $\begin{array}{l}40 \% \text { work; } 60 \% \text { work assessment } \\
\text { allowance }\end{array}$ \\
\hline $\begin{array}{l}\text { Female } \\
\text { (IDS) }\end{array}$ & 53 & Divorced/single & Nursery manager & $\begin{array}{l}\text { Lower-level } \\
\text { unlwersityofcollege }\end{array}$ & Two adult children & Sick leave the last nine months (100s) \\
\hline Male (ID3) & 45 & Divorced/single & $\begin{array}{l}\text { Disability pension (former } \\
\text { international sales) }\end{array}$ & $\begin{array}{l}\text { Upper secondary } \\
\text { education }\end{array}$ & One child & $0 \%$ \\
\hline $\begin{array}{l}\text { Female } \\
\text { (ID6) }\end{array}$ & 38 & Cohabitant & Loal authority administrator & $\begin{array}{l}\text { Lower-level } \\
\text { universitylcollege }\end{array}$ & One child & $\begin{array}{l}20 \% \text { work; } 80 \% \text { work assessment } \\
\text { allewance }\end{array}$ \\
\hline $\begin{array}{l}\text { Female } \\
\text { (ID7) }\end{array}$ & 39 & Cohabitant & Nurse & $\begin{array}{l}\text { Lower-level } \\
\text { universitýcollege }\end{array}$ & One child & Maternity leave \\
\hline $\begin{array}{l}\text { Female } \\
\text { (ID4) }\end{array}$ & 49 & Married & Shop assistant & $\begin{array}{l}\text { Upper secondary } \\
\text { education }\end{array}$ & Two children & $\begin{array}{l}40 \% \text { work } 60 \% \text { work assessment } \\
\text { allowance }\end{array}$ \\
\hline $\begin{array}{l}\text { Male } \\
\text { (ID15) }\end{array}$ & 61 & Married & Garden centre sales person & $\begin{array}{l}\text { Lower secondary } \\
\text { education }\end{array}$ & Two adult children & $\begin{array}{l}20 \% \text { work } 30 \% \text { sick leave; } 50 \% \text { disability } \\
\text { pension }\end{array}$ \\
\hline $\begin{array}{l}\text { Female } \\
\text { (ID16) }\end{array}$ & 62 & Married & Nursery nurse & $\begin{array}{l}\text { Upper secondary } \\
\text { education }\end{array}$ & Three adult children & $\begin{array}{l}40 \% \text { work } 60 \% \text { work assessment } \\
\text { allowance }\end{array}$ \\
\hline $\begin{array}{l}\text { Fermale } \\
\text { (ID14) }\end{array}$ & 59 & Divorced & Accountant & $\begin{array}{l}\text { Lower-level } \\
\text { universitykellese }\end{array}$ & Three adult children & $100 \%$ \\
\hline
\end{tabular}

\section{Data collection}

Interviews were semi-structured; the researcher used an interview guide developed by the investigators based on a review of the existing literature (see supplementary material). The interview guide was not tested before use. The second author (EBF), who is a cognitive therapist working at the clinic, conducted the interviews during the period 1 December 2019 to 30 April 2020. The interviews were tape recorded and took place at the clinic during work hours. Most of the interviews took 45 minutes to complete. Interviews ranged in length from 30 minutes to one hour.

\section{Data analysis}

Each interview was transcribed verbatim and translated into English as soon as possible following collection. The first (JH) and last author (TS) read all transcripts multiple times. They individually synthesized information from different parts of the transcripts and wrote case summaries [26]. Topics based on questions from the interview guide and other information received were discussed. Categorised collective information for all 16 case studies was further analysed to create a variable-based analysis, where the variables were organized into components of five main domains (emotions related to headaches, trauma/stressful events; headache as a driver of behaviour; family bonding and coping 
mechanisms), where headache as a driver of behaviour had three subdomains: shame; loss of identity and lack of freedom (table 2). The analysts then returned to the interview text in an iterative fashion to search for more details, commonalities and contrasts. One of the domains (emotions related to headaches) was developed before the analytic process, the others $(n=4)$ were developed during the analytic process. The transcripts were not returned to the participants for comments.

\begin{tabular}{|ll|}
\hline Table 2: Domains and subdomains in this study \\
\hline Main domains & Subdomains \\
\hline 1. Emotion related to headaches & \\
\hline 2. Trauma/stressful events & a) Shame \\
\hline 3. Headache as a driver of behavior & b) Loss of identity \\
& c) Lack of freedom \\
\hline 4. Family bonding & \\
\hline 5. Coping strategies & \\
\hline
\end{tabular}

Methodological considerations

To evaluate the trustworthiness of this qualitative study, aspects of credibility, dependability, and transferability were addressed. A total of 16 patients agreed to take part in face-to-face interviews. More than 16 interviews may have resulted in a richer variety of experiences. However, no further substantial variation was added during the final three interviews. From this we deduced that the information power was sufficient, and that a larger number of interviews would not have significantly altered the outcome of the thematic analysis [25].

Describing the research context and the participants' demographics allows readers to consider the relevance of formulated themes and transferability of the findings. Credibility was established by presenting examples of the stepwise analysis process and interview excerpts [24]. The first (JH) and the last (TS) author were responsible for the analysis process; all authors agreed on the interpretation of the results. This collaboration in the research team ensured dependability of the findings. Furthermore, this paper was written according to the criteria for reporting qualitative research [12].

\section{Results}

The following five domains were identified (emotions related to headache; trauma/stressful events; headache as a driver of behaviour; family bonding and coping mechanisms), where headache as a driver of behaviour had three subdomains including shame; loss of identity and lack of freedom. 


\section{Description of the sample}

Twelve women and four men were included in this study. The mean age of the participants was 51.2 years (range 38-68). One participant had completed basic education (primary school), four had completed secondary education and eleven had completed higher education. Only three participants worked full time, the majority $(n=10)$ worked part time because their condition was too disabling to manage a full-time job. Regarding disability pay, 5 people received work assessment allowance; 3 received disability pension and 2 were on sick leave. Two participants were retired, and one was on maternity leave. Most of the participants suffered from daily headaches complicated by fatigue (ID 1, ID2, ID3, ID5,ID 7, ID9, ID11, ID12, ID13, ID14, ID16). Only one (ID2) talked directly about pharmacological pain management.

\section{Emotions related to headaches}

Emotions are closely connected to motives and drive. They often arise when needs are either not satisfied or are hindered. Cognitive conditions are important for emotions, a person's interpretation of a situation determines which specific emotion is triggered. As such the emotion itself can act as a driving force for behaviour (26). When the participants were asked about feelings related to their headaches, a total of 14 (ID1, ID2, ID3, ID 4, ID5, ID6, ID 8, ID9, ID10, ID11, ID12, ID13, ID 15, ID16) described their headaches as a complicated experience directly related to emotions. The majority of the participants $(n=9)$ said that anger/ irritability and frustration (ID1, ID2, ID4, ID5, ID6, ID9, ID10, ID12, ID13) were dominant emotions that arose when thinking about their headaches.

Anja (ID4) signed up for a headache support group that did not help her. Talking about headaches just made them a bigger part of her life. She was angry. Shit - I get so pissed off, so angry, even at little things that don't mean anything, angry all the time! I have such a short fuse. The aching spreads to the whole of my head and then there are the daily migraines. Never a day without pain. I am never relaxed.

Bente (ID10) a wife and mother was also angry: I'm often angry and I swear a lot, I didn't used to. Everything annoys me. Little things that don't mean anything. I become easily overwhelmed, sometimes I cry, not because I'm sad but because I'm angry. Even in front of my kids, I can explode.

Kari (ID9) woke up with a headache every day. I manage daily routines quite well, even in my job a s a child minder. I just feel constantly frustrated and irritated, it is never ending.Thinking about their headaches made seven participants (ID2, ID4, ID6, ID 8, ID9, ID15, ID16) feel sad and fed up. Gro (ID2), a woman in her early forties, was resigned to not getting better. I feel numb, completely numb, like a zombie. I don't think about getting better, I just try to make it through the next hour.

Mari (ID16) usually got a headache after lunch, she had to get through all her daily tasks in the mornings. I suppress bad emotions connected to my headache. I can't allow them to emerge because the pain 
worsens, making me sad, depressed, and knocked out for several days. I've been through this so many times, so now I try to stop them [the emotions, author comment] as best I can.

When the male participants (ID3, ID11, ID12, ID15) were asked about their emotions their responses were more restrained, compared to the ladies.

Fredrik (ID3) said: I don't know. Confused? Resignation? Fatigue? It affects my feelings. Sometimes I do not have the energy to feel anything.

Arne (ID15) a retired sailor, thought that his headache was due to heavy smoking. Emotions- I don't know what I feel when I think about my headache. Exasperation perhaps.

In summary: The participants expressed a range of feelings when thinking about their headaches. Women expressed these emotions more freely than the men. Research has shown that women are usually more emotionally expressive, at least in Western cultures [27]. Men often show equal or greater levels of physiological arousal associated with feelings, compared to women. These physiological changes include an increase in blood pressure and cortisol levels, measured in response to emotionally arousing stressors [28]. This internal arousal may be a response to keeping their emotions in check.

\section{Trauma/stressful events}

In psychology, the term trauma is used in situations that adversely affect the individual's mental health or personality development [29]. A total of 10 participants (ID1, ID3, ID4, ID5, ID7, ID11, ID12, ID13, ID14, ID16) believed that trauma was the reason for their headaches. Of these, 4 participants (ID1, ID11, ID12, ID16) had headaches after physical trauma such as concussion, surgery, car crashes and whiplash.

Katrine (ID1) had suffered from headaches for more than 15 years after a concussion. It is so draining, tiring, I need quiet. I don't have the energy to discipline the children, stand up to my husband or even to keep up with chores. I feel a failure. Two car crashes resulted in head and neck pain for Jens (ID2), who has not worked for the last eight years. Injections into the nerves in my neck and back of my head stopped being effective after 4 years. Now my head feels tense and foggy.

Severe circumstances such as death of a spouse, sexual assault, or being diagnosed with a serious or terminal illness are examples of major stressful life events [30]. Such events will often result in psychological and physiological stress responses for the average person. Six participants (ID3, ID4, ID5, ID7, ID13, ID14), referred to traumatic events when talking about their headaches.

Une (ID13) related her symptoms to an event from nearly 20 years ago, when her husband left her for another woman. It hit me like a bombshell, tearing the family apart. He came home from work saying he had fallen in love with another woman and was moving to Stavanger [town in Norway, author comment]. I was paralyzed by shock. It still hurts a lot. 
Jessica (ID5) experienced a similar episode. Peter fell asleep listening to music on his phone, when I leaned over to turn it off, he woke up and grabbed it "What are you doing?" My gut twisted. He was having an affair. My shoulders started aching, I got tired from doing nothing and my forehead felt like it might explode. It's still there [the pain, authors comment], more or less.

Rose (ID7) connects her headaches to an unhappy childhood. My childhood was unstable. I did all I could to avoid being told off, shouted at and bullied. I was always anxious when mum was due home from work. Worried about what type of mood she would be in. I tried to please her. If I had been tougher, if I had had the courage to stand up to her, I am sure that I would not suffer like I do now. My sister is a totally different type of person, she stood up to mum, she doesn't have headaches like me.

In Summary: Exposure to stressful events may impact any disease through their effects on affect, behaviour and physiology [29]. There is evidence that a relationship exists between stressor exposure and a selection of common illnesses responsible for a large proportion of morbidities and disabilities [30]. Such a relationship was experienced by the majority of the participants in this study.

\section{Headache as a driver of behaviour}

\section{a) Shame}

Shame is an unpleasant self-conscious emotion, typically associated with a negative self-evaluation and withdrawal motivations. Typically, it involves feelings of distress, exposure, mistrust, powerlessness, and worthlessness [31]. Shame often arises when an individuals' actions conflict with the ideas or expectations of the individual, or society. Seven participants (ID1, ID 4, ID7, ID8, ID10, ID13) describe this emotion when talking about their headaches.

Rose (ID7) felt that she was never was good enough. As a child,mum belittled me and put me down and I let her. If I had been stronger, my headaches might never have started. In contrast, Mona (ID8) had a safe childhood, shame was not an emotion she experienced. I've always handled challenges in life well. Then again, which challenges? I've never really had any, only small everyday things. Now I'm wondering whether I have always been weak, but I didn't know, because I have never been put to the test.

Bente (ID10) felt ashamed because she often let friends down by cancelling appointments. I get fed up of explaining. It's horrible never being able to make plans with friends and family, it is impossible to predict how I will feel.

\section{b) Loss of Identity}

Many of the participants (ID 1, ID3, ID6, ID8, ID10, ID16) ( $n=6)$ felt that chronic pain has had an effect on their personalities. That is, it has turned them into someone they neither like nor want to be. Nelly (ID6) 
said: I have become another version of myself. Katrine (ID1) agreed: I have become somewhat egocentric; I don't want to be like that. I feel like I have become distant, like I am looking at myself from afar. My response patterns have changed.

Mona (ID8) feels like a washed out, weaker, duller version of herself. I lost myself, somewhere. My identity - gone, washed away by pain and illness. I don't know how to find myself again. Bente (ID10) explained that she constantly put on an act with the kids, pretending that she was healthy. I do not want them thinking that growing up with someone who is ill, is normal. So, I put on an act. I am quite good actually, but it takes its toll.

\section{c) Lack of freedom}

George Vithoulkas a Greek author and practitioner of homeopathy, postulates that a consequence of bad health is lack of freedom [32]. Five participants (ID 2, 4, 6, 7, 16) described this when talking about their complaints.

Anja (ID4) spent a brief period in prison as a result of drunk driving, the experience was followed by years of shame. I am telling you this because having a headache is like a prison sentence. It limits everything in everyday life. It limits me in all my roles as a mother, wife, cook, friend, and sexually. The pains put a stop to ambitions and goals. I'm not free.

Nelly (ID6) missed spontaneity; she spent a lot of time on her own. Work, social events and even trivial things like shopping have to be planned depending on how I feel. Unexpected events, especially things that are emotionally draining, often provoke a migraine attack.

Rose (ID7) also had to plan. Just going out for a walk means that I need to schedule time for a rest afterwards. More than a couple of tasks in a day leaves me with a pounding headache.

Marit (ID16), has had a headache for the last six years. She lamented: I miss having freedom in my life. Everything needs to be kept under control - to be predictable.

In summary: The subdomains shame, loss of identity and lack of freedom were strongly connected. Pain and the consequence of functional disability deprived the participants of the opportunity to live normal lives. With that followed a drop in social status, self-esteem, and physical well-being, which was perceived as shameful. Not being able to live their lives as they used to, was connected to loss of identity. Coping meant living a restricted and isolated life, with few activities. This was perceived as lack of freedom.

\section{Family bonding}

Family bonding is the time families spend together interacting and supporting each other. The influence of social support as a buffer for the negative effects of stressful events goes beyond mental health. 
Research shows that people with high levels of emotional support are protected against risk of mortality $[30,33]$. Seven participants (ID 2, 3, 4, 6, 7, 15, 16) said that they spent more time with their families, after their headaches started.

Nelly (ID6) said: I am closer to my family now but have distanced myself from friends. I am more emotionally open with the family. I can tell them that I am having a bad day without feeling judged. My partner and stepfather have become good friends, and I am close to my mother. We spend time together because we want to, not because we feel obliged to. It's nice. We've all bonded.

Fredrik (ID3), a former businessman and divorcee looks after his daughter part-time. I want to make sure my daughter has a good life. That's why I worked so hard before, often 70 hours a week. Now I am on disability pay, it's nothing compared to what I previously earned. I worry a lot about financial security, especially for my daughter.

Marit (ID16), talked about change, about becoming introverted, a stark contrast to the extreme extrovert she used to be. My family thinks it is OK that I've changed. They seem to respect my way of doing things now and they help me more often. I used to help them all, organize them all the time, even though my husband and children never appreciated it. Now we work together. They are learning to be independent instead of relying on me.

Although participants reported spending more time at home with close relatives, intimate relationships appear to have suffered in some cases. Five participants (ID 1,4,8,10,12) mentioned that their headaches negatively affected their sex lives.

Jens (ID12) explained: We don't have sex anymore, I can't. The pressure builds up in my head.

Mona (ID8) confided: We are no longer intimate and therefore not as close as we used to be.

Bente (ID10), still has a good relationship with her husband, even though they have agreed to sleep in separate rooms when she has bad days. It works for us, after all, we've been together for 22 years. We've agreed to have sex at least once a week. We have to make the most of my "good days." Planning sex is not ideal, but it helps us maintain a certain degree of intimacy.

By contrast, Arne (ID 15) as a former sailor lead a life where alcohol, smoking and irresponsible sex had taken its' toll on family life. I have big regrets - mostly because of the family. The bad habits didn't stop when I stopped sailing and started working on shore. It was a difficult lifestyle to change. My goodness.

In Summary: Headaches and lack of energy resulted in many participants staying at home more than they used to. Although involuntary, the situation was mostly perceived as positive regarding the strengthening of family bonds, however intimate relationships appear to have suffered.

\section{Coping strategies}


Coping strategy is understood as an action, a series of actions, or a thought process used in meeting a stressful or unpleasant situation, or in modifying one's reaction to such a situation. Coping strategies typically involve a conscious and direct approach to problems [29]. Six participants (ID 1, 3, 6, 8, 10,16) found tools to cope with the situation.

Rose (ID7) tried to focus on her daughter instead of her headaches. Regular treatments with nerve blocks partially reduced her pain. It is what it is. I have chronic headaches and they are not going to go away; I just have to live my life the best way I can.

Ella (ID14), 59-year-old women, often experienced negative emotions and feelings of worthlessness. After a humiliating episode that significantly increased her headache, she uncharacteristically had a facelift. The strange thing is that I wasn't worried or afraid. I enjoyed the doctor cutting into my face - in front of my ears - here - look. Afterwards I was really high! I didn't need painkillers and my headache was completely gone for about a week. How can I regain that positive feeling that erased my headache? I wonder whether antidepressants might have the same effect, I don't dare to discuss it with my GP. A psychologist, maybe?

Jens (ID12) finds acupuncture helpful. I still can't concentrate enough to use a computer, but now reading is no problem, - it's a big improvement.

Mari (ID16) has found a way of dealing with bad thoughts. I bake bread to distract myself. I didn't used to enjoy baking, now I love finding different recipes, the smell and all the practical things - kneading, stirring, measuring, and eating. Baking stops me thinking too much. The radio and the smell of baking calms my soul.

\section{Discussion}

This study aims to explore the lives and experiences of headache sufferers. Sixteen participants reported a life with a lot of pain resulting in disability. Many of the participants $(n=10,62.5 \%)$ were not able to work full time and the majority had some type of disability pension. Ten people (62.5\%) believed that trauma was the reason for their headaches, they expressed anger, frustration and irritability when thinking about their headaches. Shame and a loss of identity were much talked about and strongly identified as being a consequence of chronic illness. Many suffered from lack of freedom and flexibility because planned activities often had to be cancelled in the event of increased pain, forcing them to arrange their lives around their headaches. Almost half of the participants $(n=7,44 \%)$ reported that keeping contact with friends was difficult, however family relationships mostly became closer.

\section{Other studies}

Although headaches were reported as draining, some participants $(n=6,37,5 \%)$ found coping tools such as medical treatments, hobbies, or other focus points. 
The impact of reducing stress is unknown, however stress management and relaxation techniques are validated treatments for migraines and may be especially helpful for patients who frequently experience stress or cope with it poorly [14]. Focus on the good things in life in order to reduce stress, is a finding reported by two studies conducted in Sweden $[20,21]$.

A systematic review of qualitative literature of the lived experience of people with a chronic headache disorder included 4 studies [23]. Fifty-two of the 73 participants were female, the proportion of women to men was similar to our study. They also reported that headaches led to behaviours such as avoidance of planning or having to stop doing things, leading to a feeling of loss of control over their lives, findings also common to our study. When headaches act as a driver of behaviour, it also affects relationships with people around headache sufferers. In our study it mostly led to strained relationships with friends, a finding described in a study from Jonsson et al. [34]. Many of the issues raised in our study such as impaired quality of life, the effect on others, uncertainty and the emotional impact of the condition, resonate with a multitude of other chronic pain conditions, such as low back pain [35] and fibromyalgia [36]. Such conditions, including chronic headaches are common disorders of a pain matrix, which is often devalued by others [37], and where chronic pain is considered low status, compared to acute pain. These invisible chronic conditions are often not backed up by biological indicators, blood tests or scans, denying sufferers objective measurements to support their condition [38]. Clinicians often encounter patients who are left with only their personal stories, subjective visual analogue scale estimates and the hope of finding a good doctor.

\section{Theory of life course approach and embodiment}

A total of ten participants (62.5\%) believed that trauma or stressful events were the reasons for their headache. Four participants reported headaches after physical trauma and six referred to psychological events. Similar findings have been reported in previous research regarding chronic headaches and migraine $[1,14]$. Stressful events are considered to influence disease risk (1). Contribution to the onset and maintenance of pain syndromes by affective dysregulation, can manifest itself in anxiety, fear, and depression. These emotional stress factors can further be compounded by biological and behavioural stress factors such as drinking, eating disorders and smoking [30]. Definitions of what constitutes stressful events vary but are generally considered to be major events such as torture, sexual trauma, murder or the loss of a child. Rarely are common everyday events we have encountered in this study, such as infidelity, divorce, humiliation, accidents and unmet emotional needs considered to be warning signs, where loss of health is concerned. These findings correlate with the life course approach and the theory of embodiment discussed earlier, describing how extrinsic and biological factors offer a complex understanding of chronic diseases [39].

Most research considering stressful events and trauma focuses on episodes from childhood. There is little evidence regarding adult trauma, and ethical considerations prohibit conducting experimental studies in humans, of the effects of enduring stressful events. 


\section{Strengths and limitations}

This study should be interpreted considering its strengths and limitations. Qualitative analysis provides insights into how participants understand and interpret situations, but it cannot be used to establish associations [12]. Sixteen participants agreed to be part of an interview. Having more than 16 interviews may have resulted in an extended variety of experiences. However, no further substantial variation was added during the final three interviews, leading to the conclusion that the information power was sufficient, and that a larger number of interviews would not have significantly altered the outcome of the thematic analysis $[12,40]$. Moreover, the in-depth interviews provided rich, complex material and the participants demonstrated striking similarities in their personal histories, concerns and strategies. However, the study is based on data from a selected group of participants recruited via the pain clinic at Vestfold Hospital Trust. The present findings may not be representative for headache sufferers from other areas in Norway.

\section{Implication for clinical practice and further research}

Chronic headache is a complex disease. Based on data from this study, treatment should include a holistic approach such as pain management, counselling/psychotherapy, and family support, aimed at multi-symptom reduction and an increase in function.

In this study the majority of participants associate their condition with some kind of stressful event, either during childhood or as an adult. These events need to be identified by clinicians, as do ongoing events that maintain or exacerbate symptoms. Only by identifying and addressing such elements will patients with chronic pain receive help to achieve a higher level of resilience.

Only three of the 16 participants in this study were men. Information given during interviews by the men was more pragmatic and less emotional than information given by the women. It is possible that clinical approaches need to be adjusted according to gender. Also, the possibility that other methods of collecting qualitative information, such as anonymous written statements, may be more appropriate in order to gain broader and richer information from men. Moreover, chronic pain impacts the entire family. Research needs to be developed as to what extent family members should be involved in patient care, health education and care.

\section{Conclusion}

This study demonstrates that chronic headaches restrict sufferers lives, resulting in emotional and behavioural changes. Traumatic events of varying degrees throughout the course of life can initiate and maintain symptoms, which may become chronic and thereby have socio economic consequences, for individuals and society in general. 
These patients need a multidisciplinary treatment approach, including traditional pain management and evidence- based mind-body modalities. Clinicians need to have an increased awareness as to the complexity of chronic headaches.

\section{Abbreviations}

GP

General practitioner

HUNT

Nord-Trøndelag health study

ID

Identifier numbers

WHO

World health organization

\section{Declarations}

\section{Acknowledgements}

We want to express our gratitude to the patients who participated in this study. The publication charges for this article have been funded by a grant from the publication fund of UiT, The Arctic University of Norway.

\section{Authors' contributions}

$\mathrm{JH}$ developed and designed this study and performed the data analysis. EBF conducted the interviews. TS performed the data analysis together with $\mathrm{JH}$ and she drafted the manuscript. All authors have read and approved the last version of the manuscript.

\section{Funding}

This research did not receive any specific grant from funding agencies in the public, commercial, or notfor-profit sectors

\section{Availability of data and materials}

The datasets generated and/or analyzed during the current study are not publicly available because they contain confidential and sensitive data, but anonymously labelled data is available on request.

\section{Ethics approval and consent to participate}

Written informed consent was obtained from all participants before the interviews started, and all were informed that they could withdraw from the study for no reason. The study was approved by the 
Norwegian Centre for Research Data (NSD) with the reference code: 754483. This study meets the standard of the Helsinki Declaration of 1975 last revised in 2013 (39).

Consent for publication

Consent to publish was obtained from the participants.

\section{Competing interests}

The authors declare no competing interests.

\section{Author details}

${ }^{1}$ Department of Anaesthesia, Pain Clinic, Vestfold Hospital Trust, 3116, Tønsberg, Norway

${ }^{2}$ National Research Center in Complementary and Alternative Medicine (NAFKAM), Department of Community Medicine, Faculty of Health Sciences, UiT The Arctic University of Norway, Hansine Hansens veg 19, 9019 Troms $\emptyset$, Norway.

\section{References}

1. Migraine headaches in adults [https://bestpractice.bmj.com/topics/enus/10/pdf/10/Migraine\%20headache\%20in\%20adults.pdf]

2. Lim SS, Vos T, Flaxman AD, Danaei G, Shibuya K, Adair-Rohani H, Amann M, Anderson HR, Andrews $\mathrm{KG}$, Aryee $\mathrm{M}$ et al: A comparative risk assessment of burden of disease and injury attributable to 67 risk factors and risk factor clusters in 21 regions, 1990-2010: a systematic analysis for the Global Burden of Disease Study 2010. Lancet 2012, 380(9859):2224-2260.

\section{Neurological disorders: public health challenges}

[https://www.who.int/mental_health/neurology/neurodiso/en/]

4. Stovner LJ, Zwart JA, Hagen K, Terwindt GM, Pascual J: Epidemiology of headache in Europe. European Journal of Neurology 2006, 13(4):333-345.

5. Steiner TJ, Scher Al, Stewart WF, Kolodner K, Liberman J, Lipton RB: The prevalence and disability burden of adult migraine in England and their relationships to age, gender and ethnicity. Cephalalgia 2003, 23(7):519-527.

6. Guidelines [HIS 3rd edition], [www.ihs-headache.org/]

7. Linde M, Gustavsson A, Stovner LJ, SteinerTJ, Barré J, Katsarava Z, Lainez JM, Lampl C, LantériMinet M, Rastenyte D et al: The cost of headache disorders in Europe: the Eurolight project. Eur J Neurol 2012, 19(5):703-711.

8. Katsarava Z, Schneeweiss S, Kurth T, Kroener U, Fritsche G, Eikermann A, Diener HC, Limmroth V: Incidence and predictors for chronicity of headache in patients with episodic migraine. Neurology 2004, 62(5):788-790. 
9. Hagen K, Stovner LJ, Zwart AJ: Time trends of major headache diagnoses and predictive factors. Data from three Nord-Trøndelag health surveys. The Journal of Headache and Pain 2020, 21(1):24.

10. Haag G, Diener HC, May A, Meyer C, Morck H, Straube A, Wessely P, Evers S: Self-medication of migraine and tension-type headache: summary of the evidence-based recommendations of the Deutsche Migräne und Kopfschmerzgesellschaft (DMKG), the Deutsche Gesellschaft für Neurologie (DGN), the Österreichische Kopfschmerzgesellschaft (ÖKSG) and the Schweizerische Kopfwehgesellschaft (SKG). J Headache Pain 2011, 12:201-217.

11. Cameron C, Kelly S, Hsieh SC, Murphy M, Chen L, Kotb A, Peterson J, Coyle D, Skidmore B, Gomes T et al: Triptans in the Acute Treatment of Migraine: A Systematic Review and Network Meta-Analysis. Headache 2015, 55 Suppl 4:221-235.

12. Quinn Patton M: Qualitative Research \& Evaluation Methods 3 Edition edn. London: Sage Publications, Inc; 2002.

13. Sutin AR, Costa PT, Wethington E, Eaton W: Perceptions of stressful life events as turning points are associated with self-rated health and psychological distress. Anxiety, Stress, \& Coping 2010, 23(5):479-492.

14. Scher Al, Stewart WF, JA R, Lipton RB: Factors associated with the onset and remission of chronic daily headache in a population-based study. Pain 2003, 106(1):81-89.

15. Smith GD, Hart C, Blane D, Hole D: Adverse socioeconomic conditions in childhood and cause specific adult mortality: prospective observational study. BMJ 1998, 316(7145):1631-1635.

16. Bourdieu P: Texts of Sociology. Athens: Delfini; 1994.

17. Asimaki A, Koustourakis $G$ : habitus: An attempt at a through analysis of a controversial concept in Pierre Bourdieu's theory of practice. Social Sciences 2014, 3(4):121-131.

18. Bourdieu P: Practical discourses for the theory of action. Athens: Plethron; 2000.

19. Bourdieu P, Chartier R: Le sociology et l' historien. Marseille: Agone; 2010.

20. Rutberg S, Öhrling K: Migraine-more than a headache: women's experiences of living with migraine. Disabil Rehabil 2012, 34(4):329-336.

21. Rutberg S, Ohrling K, Kostenius C: Travelling along a road with obstacles: experiences of managing life to feel well while living with migraine. International journal of qualitative studies on health and well-being 2013, 8:1-9.

22. Seng EK, Holroyd KA: Optimal Use of Acute Headache Medication: A Qualitative Examination of Behaviors and Barriers to Their Performance. Headache: The Journal of Head and Face Pain 2013, 53(9):1438-1450.

23. Nichols VP, Ellard DR, Griffiths FE, Kamal A, Underwood M, Taylor SJC, Chess team: The lived experience of chronic headache: a systematic review and synthesis of the qualitative literature. $B M J$ open 2017, 7(12):e019929-e019929.

24. Malterud K: Kvalitative metoder i medisinsk forskning. En innføring. English: Qualitative methods in medical research. An introduction, 3. edn. Oslo: Universitetsforlaget; 2011. 
25. Malterud K, Siersma VD, Guassora AD: Sample size in qualitative interview studies: guided by information power. Qual Health Res 2016, 26(13):1753-1760.

26. Baxter P, Jack S: Qualitative case study methodology: Study design and implementation for novice researchers. The Qualitative Report 2008, 13(4):544-559.

27. Chaplin TM: Gender and Emotion Expression: A Developmental Contextual Perspective. Emot Rev 2015, 7(1):14-21.

28. Chaplin TA, Hong KA, Bergquist K, Sinha R: Gender Differences in Response to Emotional Stress: An Assessment Across Subjective, Behavioral, and Physiological Domains and Relations to Alcohol Craving. Alcoholism: Clinical and Experimental Research 2008, 32(7):1242-1250.

29. Raaheim A, Raaheim K: Psykologiske fagord. English: Psychological vocabulary. Bergen: Fagbokforlaget Vigmostad \& Bjørke AS; 2004.

30. Cohen S, Murphy MLM, Prather AA: Ten surprising facts about stressful life events and disease risk. Annu Rev Psychol 2019, 70:577-597.

31. Tracy J, Robins R: Self-conscious emotions: Where self and emotion meet. In: Frontiers of social psychology The self. edn. Edited by Sedikides C. London: Psychology Press; 2007: 187-209.

32. Vithoulkas G: Homeopathy, Medicine of the New Man. New York: Arco Publishing, INC.; 1983.

33. Rosengren A, Orth-Gomér K, Wedel H, Wilhelmsen L: Stressful life events, social support, and mortality in men born in 1933. Bmj 1993, 307(6912):1102-1105.

34. Jonsson P, Jakobsson A, Hensing G, Linde M, Moore CD, Hedenrud T: Holding on to the indispensable medication -A grounded theory on medication use from the perspective of persons with medication overuse headache. The Journal of Headache and Pain 2013, 14(1):43.

35. Froud R, Patterson S, Eldridge S, Seale C, Pincus T, Rajendran D, Fossum C, Underwood M: A systematic review and meta-synthesis of the impact of low back pain on people's lives. $B M C$ Musculoskeletal Disorders 2014, 15(1):50.

36. Bernard AL, Prince A, Edsall P: Quality of life issues for fibromyalgia patients. Arthritis Care \& Research 2000, 13(1):42-50.

37. Glenton C: Chronic back pain sufferers-striving for the sick role. Social Science \& Medicine 2003, 57(11):2243-2252.

38. Joachim G, Acorn S: Stigma of visible and invisible chronic conditions. Journal of Advanced Nursing 2000, 32(1):243-248.

39. Krieger N: A glossary for social epidemiology. J Epidemial Community Health 2001, 55:693-700.

40. Kvale S, Brinkmann S, Anderssen TM, Rygge JF: Det kvalitative forskningsintervju. English: The qualitative research interview. Oslo: Gyldendal akademiske forlag; 2009.

\section{Supplementary Files}

This is a list of supplementary files associated with this preprint. Click to download. 
- Interviewguideenglish.docx

Page $20 / 20$ 